Assessing faculty productivity by research impact: Introducing Dp2 index

Chekitan S. Dev ${ }^{1}$

\author{
H. G. Parsa*2 \\ Rahul A. Parsa ${ }^{3}$ \\ Milos Bujisic ${ }^{4}$
}

${ }^{1}$ Services Marketing, School of Hotel Management, Cornell University, Ithaca, NY, 14853

${ }^{2}$ Fritz Knoebel School of Hospitality Management, Daniels College of Business, University of

Denver, Denver, CO, 80210

${ }^{3}$ Principal Financial Group Distinguished Professor of Actuarial Science and Statistics College of

Business and Public Administration, Drake University, Des Moines, IA, 50311

${ }^{4}$ Hospitality Management, Consumer Sciences, Ohio State University, Columbus, OH, 43210

*Correspondence

hparsa@du.edu 


\begin{abstract}
Assessing hospitality faculty-research output has become a subject of research in its own right. Unfortunately most of the currently available assessment instruments are limited in their ability to consider consistency, productivity, originality, and longevity of productivity in hospitality research. Thus, this article introduces a new research productivity index using secondary sources of data for evaluating faculty research productivity, based on four criteria: quantity, quality, consistency, and longevity. The proposed Dp2 index uses publicly available secondary data sources in assessing the research productivity of hospitality faculty. The proposed Dp2 index is parsimonious, effective, flexible, adaptable, and easy to implement.
\end{abstract}

\title{
Keywords
}

research productivity, index, faculty research, Dp2 index, hospitality research 


\section{Assessing faculty productivity by research impact: Introducing Dp2 index}

\section{Introduction}

What distinguishes the best faculty research? Is it possible to evaluate scholarly research objectively? This article introduces a measure of faculty research productivity that aggregates scores based on four criteria: quality, quantity, consistency, and longevity, which we call the Dp2 index. We measure quality by the number of citations a scholar's work elicits, quantity by the number of publications the scholar has produced, consistency by the number of publication without long “research gaps,” and longevity by the number of citations and publications over an extended period. The Dp2 index will enable researchers to measure faculty productivity more broadly and with greater reliability, which in turn should enable academic departments to make better hiring, promotion, and tenure decisions. It is highly adaptable to the needs of individual academic units. This tool should prove especially useful for evaluating faculty output in younger academic disciplines in which track records are shorter, and for this reason the field of hospitality research provides an ideal source of data for testing the viability of the Dp2 index as we measure faculty productivity in this area.

Understanding and evaluating the quality and quantity of faculty research, or faculty productivity, has attracted considerable academic attention in a wide range of academic disciplines (Jogaratnam, McCleary, Mena, \& Yoo, 2005; Reed, 1995; Roche \& Smith, 1978). A number of studies have developed rankings of faculty research contributions using number of publications as the primary criterion (Adkins \& Budd, 2006; Blair, Cottle, \& Wallace, 1986; Bloom \& Klein, 1995; Brown \& Gardner, 1985; Davis \& Papanek, 1984; Garfield, 1979; Meho \& Sonnenwald, 2000; Reed, 1995; Roche \& Smith, 1978). Such studies have been conducted in the field of hospitality as well (Hall, 2011; Law \& van der Veen, 2008; Losekoot, Verginis, \& 
Wood, 2001; Park, Phillips, Canter, \& Abbott, 2011; Pechlaner, Zehrer, Matzler, \& Abfalter, 2004; Rutherford \& Samenfink, 1992; Ryan, 2005; Schmidgall \& Woods, 1993; Sheldon, 1990). In 2011, Beck, Kim, and Schmidgall (2011) extended this work by analyzing the effects of the quantity and quality of faculty research on salary, reappointment, promotion, and tenure decisions in international hospitality programs. There is a general agreement that research quality and quantity are two critical factors in faculty evaluation for promotion and tenure.

In addition to measuring faculty productivity by number of publications, the quality of research output has been gauged by the stature of journals in which studies are published, and by the number of times an article is cited in the literature, adding a qualitative measure—citation analysis—-to shed more light on the impact of research. "Quality in this sense is generally defined as a measure of the extent to which an idea or an author has contributed to the progress of knowledge" (Meho \& Sonnewald, 2000, p. 123). Citation of a refereed article in a respected journal is considered an important indication of the quality of that particular article. Citation analysis is deemed appropriate because it is based on the impact of the publication on the advancement of knowledge. Impact is defined by the scientific community as the number of times an article is cited in studies following the publication of the article (Harzing, 2011). Thus, the higher the citation number, the greater is the impact of an article. As a result, the use of citations as a measure of the impact of a faculty member's work has gained momentum.

Blair et al. (1986) used citation analysis to assess faculty in economics departments. Bloom and Klein (1995) argued that citation analysis is necessary for comparing the quality of research in schools of social work. Reed (1995) used citation analysis to compare the quality of publications (see also Adkins \& Budd, 2006; Bloom \& Klein, 1995; Brown \& Gardner, 1985; Davis \& Papanek, 1984; Garfield, 1979). In the marketing literature, citation analysis has been 
used to compare award-winning articles (Hubbard, Norman, \& Parsa, 2010; Stremersch, Veniers, \& Verhoef, 2007). Some authors have even argued that one highly cited article in a peerreviewed journal should carry the same weight as several less-cited peer-reviewed articles to account for publication quality (Jorgaratnam, Chon, McCleary, Mena, \& Yoo, 2005; Law, Leung, \& Buhalis, 2010; Park et al., 2011). Singh, Haddad, and Chow (2007, p. 319) stated that "both administrators and the management discipline will be better served by efforts to evaluate each article on its own merits rather than abdicate this responsibility by using journal rakings as a proxy for quality.” Because articles published in a journal can vary in their individual impact, using citation analysis to measure the impact of an article, instead of simply noting the ranking of the journal in which it appears, is becoming recognized as a meaningful measure of research quality. However, simple citation analysis (i.e., counting citations) can often be misused. Kostoff (1998) argued that a simple count of citations is often insufficient, concluding that in-depth analysis of published research is required to determine the research quality. Self-citations, crosscitations, number of authors per publication, and how long an article has been published should all be taken into account when evaluating the quality of research. Cross-citations happen when an author's work is cited by others in more than one form of publication such journals, books, conference proceedings, working papers, etc. Cross-citations also include on-line journals, databases, book chapters, etc. (Elliott, Morgan, Fuqua, Ehrhardt, \& Poling, 2005).

Even when citation analysis is used, it is difficult to measure the relative quality of research. In most of the universities, the quality of faculty research is typically evaluated using a peer-review process. In other words, other faculty, generally representing the same discipline at other institutions, evaluate the research quality based on subjective criteria, that is, their judgment of quality based on their knowledge of the history and development of the discipline. 
These evaluations are then combined with objective quantitative criteria such as number of publications to produce an overall research quality assessment (Meho \& Sonnenwald, 2000), and are often used to assess faculty productivity. Such assessment procedures suffer, however, from a lack of objectivity. In order to avoid the variability and ambiguity of such rankings, Clarke (2002) developed a set of instructions for how faculty assessment should be created and presented.

Hospitality faculty ratings are not free of such problems. Ferreira, DeFranco, and Rappole (1994) examined the impact of journal quality on perceptions of publication quality expressed by hospitality faculty. They reported that rankings of refereed journals were used in only $37 \%$ of institutions in their study as indicators of the quality of published work. Instead, quantity of journal publications without regard to quality was used far more frequently. Law and Chon (2007) argue, however, that citation counts and number of published articles are only a partial proxy for research quality and are subject to bias, concluding that "input, service, and other output types are also an essential part of academic research” (p. 1203).

Given the lack of a universally adopted measure of the quality of faculty research, the objective of this study is to develop a measure of faculty research impact that can serve as an objective measure of quality that can be used for assessing faculty productivity. In particular, the study analyzed the research output of hospitality and tourism faculty using the above mentioned Dp2 index, and creates an anonymous listing of faculty whose research has had the most impact. We intend the Dp2 index to allow assessment of faculty based on a combination of quality and quantity indicators adjusted for time and consistency. This article thus introduces a novel and an objective way to measure faculty-research impact based on the four above mentioned criteria: quantity, quality, longevity, and consistency of research. 


\section{Literature Review}

In most previous studies, researchers have focused on the quantity of publications and the prestige of the refereed journals in which they are published (McKercher, 2005, 2012; McKercher, Law, \& Lam, 2006) as a means of assessing, first, the quality and reputation of the journals and, second, the quality of faculty research. It is assumed that research published in higher-ranking journals exhibits higher quality compared with research published in what are considered to be second- or third-tier journals. Although this criterion can often lead to undervaluation of high-quality research published in lower-ranking journals, it provides a simple and easily quantifiable criterion for publication quality.

Journals are listed and compared using a variety of Research Assessment Measures (RAMs), and, as noted by Chang and McAleer, 2012, the most common RAMs are: "2-year impact factor including journal self-citations (2YIF), 2-year impact factor excluding journal selfcitations (2YIF*), 5-year impact factor including journal self-citations (5YIF), Immediacy (or zero-year impact factor (OYIF)), Eigen factor, Article Influence, C3PO (Citation Performance Per Paper Online), h-index, PI-BETA (Papers Ignored - By Even The Authors), 2-year Selfcitation Threshold Approval Ratings (2YSTAR), Historical Self-citation Threshold Approval Ratings (H-STAR), Impact Factor Inflation (IFI), and Cited Article Influence (CAI)” (p. 3). Most of these indicators are based on the average number of citations per publication.

\section{Citations as a method for assessing faculty productivity}

Research productivity continues to increase in importance as a measure of faculty effectiveness in every field (Hamermesh, Johnson, \& Weisbrod, 1982). Adkins and Budd (2006, p. 376) stated that "the contribution to a field's body of knowledge is the purpose of academic 
units” (italics added). Quantifying research contributions continues to be a contentious and often divisive issue. One commonly used measure of impact is total number of citations, which assumes that the quality of publications will dictate the total number of citations received per publication (Adkins \& Budd, 2006). Thus, the use of citations to rank faculty is considered an objective indication of an assessment that has traditionally involved subjective judgments.

However, there is little uniformity across fields of research or even topics within the same field regarding how many publications or citations suffice as a measure of research quality. For example, a researcher who works within a specialized, narrow field of research may not receive as many citations as a researcher in a more popular or mainstream field even if the research is of the highest quality. On the other hand, certain types of published studies, such as meta-analyses, scale development papers, and integrative review articles tend to receive many citations often without making significant theoretical or empirical advances. In addition, some citations in basic sciences, medical and public health sciences, defense, and technology are driven by federal funding agencies. For example, often some major research funding agencies, governmental and private, prefer citation of results and conclusions from previous studies they have funded earlier, perpetuating high citation numbers for their own funded studies. Thus, depending exclusively on citations in evaluating the quality of research should be approached with caution.

Hayes (1983) identified another potential problem with citation counts, arguing that use of the Social Sciences Citation Index (SSCI) should provide a reliable measure of the number of citations and a good starting point for measuring research quality (see also Reed, 1995). However, Adkins and Budd (2006) argued that "(1) it is difficult and enormously time consuming to account for all publications by a substantial number of individuals; (2) not all 
publications are equal in that a one-page response to another author is not the same as a book; (3) secondary sources that can be used to track publications and citations are not exhaustive; and (4) citation to the works of others can be made for numerous reasons” (p. 375).

Harzing (2011, p. 3) states that low citation numbers can be caused by any of the three factors: (1) "Working in a small field,” an emerging discipline, or a highly focused and very specialized area (we view hospitality research as an emerging field in which citations occur with less frequency); (2) publishing in a language other than English, as articles published in English are cited on average more frequently than those published in other languages. More articles are published in English, and articles published in languages other than English suffer from lack of instant translation support; and (3) publishing mainly in books. Research articles published in books are less likely to be cited as compared with articles published in refereed journals. Moreover, most research-intensive academic institutions assign less weight to books compared with articles published in refereed journals in evaluating faculty research productivity.

\section{Assessment of hospitality faculty research}

Rutherford and Samenfink (1992) were among the first to show that research has an important impact on tenure and promotion of hospitality program faculty. They created an assessment system to rank order hospitality and tourism faculty based on the total number of appearances an author had made in refereed hospitality and tourism journals. Additionally, adjusted appearances were used to distinguish between single-authored and multi authored articles. Almost two decades later, Park et al. (2011) analyzed the productivity of authors, universities, and countries using research contributions to top hospitality and tourism journals. They considered publications in the six most-often cited hospitality and tourism journals: 
Journal of Hospitality \& Tourism Research, International Journal of Hospitality Management, Cornell Hospitality Quarterly, Tourism Management, Annals of Tourism Research, and Journal of Travel Research. In a recent study of research productivity among hospitality faculty, Way, Harrington, and Ottenbacher (2012), like Park et al., focused narrowly on hospitality and tourism journals and ignored broader fields that study management, marketing, and other businessrelated topics.

The methodology used by Way et al. (2012), and Park et al. (2011) suffers from several problems. First, hospitality faculty members are increasingly pursuing interdisciplinary research and publishing in journals outside of the tourism and hospitality field (Jamal, Smith, \& Watson, 2008). The impact factor of a broader-based journal may be higher compared with even the most highly reputed tourism and hospitality journals. Therefore, focusing only on hospitality and tourism journals tends to introduce bias into faculty assessment, favoring faculty who publish exclusively in tourism and hospitality journals while putting those who publish in non-hospitality journals at a disadvantage.

Impact factors are reported by most major journals as an indication of the academic quality of the articles in those journals. It is commonly accepted that impact factors represent an objective indication of journal quality. The Impact Factor construct was introduced formally by the Institute for Scientific Information as one of the three factors used to evaluate the quality of an academic journal, along with the Immediacy Index and Citation Half Life. According to Amin and Mabe (2000), "The impact factor is a measure of the relative size of the citation curve in years 2 and 3. It is calculated by dividing the number of current citations a journal receives to the articles published in the two previous years by the number of articles published in those same years." Impact Factor can be affected by "sociological and statistical factors. Sociological factors 
include the subject area of the journal, the type of journal (letters, full papers, reviews), and the average number of authors per article (which is related to subject area). Statistical factors include the size of the journal and the size of the citation measurement window” (Amin \& Mabe, 2000). Although Impact Factor is a good measure of the quality of a journal, it is not perfect. A journal's Impact Factor can fluctuate irrespective of changes in research direction or journal quality. In other words, journals that are making good progress with respect to quality could see their Impact Factor drop, while journals that are slipping could see their impact factor rise. One explanation for this phenomenon is that impact is a relative measure that is time sensitive. Since Impact Factor is not an absolute measure it is also affected by the relative performance of other journals in the same discipline. This supports using all three measures while assessing the quality of a journal.

In addition to the problem of "limited high-quality journals" for hospitality and tourism faculty research assessment, these assessment studies have suffered an additional problem. Most previous research has used either number of publications or number of citations per faculty exclusively. Unfortunately, both these criteria suffer from methodological weaknesses.

Publication numbers indicate the quantity of research output while completely ignoring the quality of the publications. For its part, citation counts ignore the longevity and quantity of research activity. In some instances, citations have more to do with the popularity of a topic than the quality of an article, which is known as "hot button research syndrome.” In addition, citations are also affected by publication channel and access. For example, popular journals supported by well-established publishers enjoy greater access to knowledge distribution channels such as Web of Science, SCOPUS, and others compared with journals published by academic institutions or associations with limited media and knowledge distribution resources. The above mentioned 
advantage of publishing in English might also misrepresent the quality of a given article. And articles published in popular and highly ranked journals tend to receive more citations compared with those published in lesser-known journals, implying that citations depend to a considerable extent on the publication channel.

The above statement can be illustrated by the following example from the field of physics. Prof. Louis Néel Hannes Alfven received Nobel Prize in physics in 1970 for his published work in the magnetohydrodynamics field. He is the father of the magnethydrodynamic wave commonly called Alfven Wave which challenged the then prevailing Newtonian principles in physics. In 1930s, his original research was not accepted for publication by leading journals in physics of that era as it challenged the prevailing Newtonian theories of that period (Murthy, 2010, From a personal conversation with a student of Prof Haans Alfven, Sweden, Nobel Laureate in Physics in 1970). Consequently he was forced to choose lesser-known journals and a book format to share his research ideas which received greater acceptance later. And in 1970 he received Nobel Prize in physics for the same work that was earlier rejected by the main stream physics journals in the 1930s. According to Fälthammar and Dessler (2013) “....... in 1939 he wrote a remarkable article in which he proposed a theory for magnetic storms and auroras. This article, which lays out presently accepted basic ideas on how plasma flows around a dipole magnetic field to create Birkeland currents that flow in and out of the auroral zone, was rejected by the predecessor of the Journal of Geophysical Research because it disagreed with the theories of Sydney Chapman and his colleagues. Thus, he eventually turned to journals that did not enjoy international readership. Most of his ideas were finally made known to the scientific community through his marvelous book, Cosmical Electrodynamics, published by the Oxford University Press in 1950. This book has been the inspiration for a number of books by others having similar 
approaches, similar titles” (Fälthammar \& Dessler, 2013; Murthy, 2010, personal communication). Thus, research quality and number of citations are affected by the source of publication outlets as shown in case of Professor Alfven's research.

Moreover, again as we have already noted, specialized articles such as scale development articles, integrative literature review articles, and meta-analyses tend to receive more citations mostly because of their usefulness as a citation source than as an indication of quality of the article in advancing the research thought. Thus, exclusive usage of citations in assessing faculty productivity has limitations.

An important criterion for measuring faculty research impact via citations is longevity. Most faculty members are expected to continue publishing high-quality research articles over a long period of time; continuous and intense work on a given problem leads to theoretical and empirical advances in a given field of study. As Iyengar (2010), professor of marketing at the Columbia University, noted, a scholar undergoing the tenure process is like a mouse locked up in a cage with food and water and set on a treadmill for six years. After six years of tenure track work the mouse is set free when the tenure gate opens, but while some tenured mice enjoy the freedom of open gates, others prefer to get back on the treadmill quickly to keep up with the research competition and continue to flourish beyond tenure. Unfortunately, those who enjoy their freedom too much simply leave the cage and disappear in the woods, never to be heard from again. Thus, longevity in research publication is rightly considered and highly regarded as an important criterion for evaluating faculty for tenure and promotion decisions.

Most current faculty evaluation tools, unfortunately, do not evaluate longevity in faculty productivity. As a result, some faculty members who produce high citation/publication numbers prior to achieving tenure may receive higher rankings in the short run but fail to remain 
impactful in the long run, making such rankings less reliable, less meaningful, and less useful in the long run. Moreover, consistent high-quality research over a long period is the most commonly cited criterion for promotion to the rank of full professor in most academic programs. Yet currently available citation and publication analyses do not consider longevity and consistency in their evaluation methods. Therefore, there is a need for the development of a new index that would measure the quality and quantity of research with greater rigor as well as the consistency and longevity necessary for the appropriate ranking of faculty.

Furthermore, a majority of previous studies have counted publications in only a limited number of journals. Since hospitality faculty are increasingly pursuing interdisciplinary research and publishing in non-hospitality journals, departments that consider hospitality journals exclusively may be doing a disservice to and jeopardizing the careers of some faculty members. In addition, administrators who rely exclusively on hospitality journal rankings can be unintentionally misled by this omission. Thus, the current article provides an alternative method for assessing the research productivity of faculty using the following criteria:

1. Publications: total number of referred academic journal publications in all relevant fields.

2. Citations: total number of citations for all refereed publications from all relevant fields.

3. Consistency: consistency of research quality as measured by absence of gaps in contributions over an extended time.

4. Longevity: total number of publications and citations over an extended period.

\section{Faculty impact metrics}

The literature features a wide variety of productivity indices to assess faculty research productivity. We review some commonly used indices below. 
h-index:

The h-index was introduced by Hirsch (2005) to provide a single index of a scholar's productivity that takes into consideration all publications and citations, the quality of the journals in which the scholar has published, and the scholar's impact factor. It was quickly adopted by various citation services, and, although it has a bias against popular publications, it is widely accepted (Hirsch, 2005). The h-index tends to be less appropriate for young researchers, especially in the social sciences (Harzing, 2011) and is considered more appropriate for established faculty such as Nobel Laureates, for which it was originally tested.

g-index:

The g-index was introduced by Egghe (2006) to address some of the limitations of the hindex. It retains all the positive elements of the h-index and gives greater weight to highly cited articles. For example, if a scientist has published 30 articles and those articles have been cited 900 times, the scientist would have a g-index of 30. Thus, it is an improvement over the h-index (Harzing, 2011).

M-Quotient:

To overcome the limitations of the h-index, Hirsch introduced the M-Quotient (Thompson, Callen, \& Nahata, 2006). The M-Quotient allows for easier comparisons between new scientists and established faculty, but it is discipline specific and does not allow for comparisons across disciplines, thereby penalizing faculty who publish on interdisciplinary topics, which happens frequently in hospitality studies. 


\section{Variations:}

One of the problems with the h-index is its inability to address the issue of co-authorship and multiple authors. Alternatives to the h-index (in addition to the g-index) have been suggested, for example by Btista, Campitelli, Konouchi, and Martinex (2006) and Harzing and van der Wal (2008). These alternatives include the individual-h and other variations.

In summary, Thompson et al. (2009) stated that "Caution should be exercised when comparing metrics across colleges with varying missions and goals. The skewed nature of publication data should also be taken into account. As a rough guide, approximately $20 \%$ of faculty members from a given college or department will normally account for $80 \%$ of the publications. Therefore, measures of central tendency should be evaluated with caution.” For more discussion of various metrics included in "Publish or Perish"—a software application that enables authors to calculate their publication impact—refer to Harzing (2011, pp. 8-12).

The above discussion makes it clear that most currently used citation indices are limited in some respects. Most indices are affected by limitations that can be ascribed to the algorithmic logic used in related calculations. In addition, exclusive dependence on either total citations or total number of publications, as is often the case in assessing faculty research productivity, has been found to be less than useful and less than fair in making important decisions that could affect faculty careers. Thus, there is a need for an index that is effective, less susceptible to algorithmic limitations, easy to implement, adaptable across disciplines, customizable to the specific needs of an institution, not affected by geographic policy differences in evaluating faculty research productivity, and effectively meets the administrative needs of smaller and larger institutions alike. 


\section{Proposed Dp2 index:}

We introduce a new index to overcome some of the abovementioned limitations of commonly used in faculty productivity indices. The proposed Dp2 index was developed as a part of our effort to bring greater objectivity and efficiency to the process of assessing faculty productivity. Our objective is not to rank faculty but to present a valid, transparent, and objective measure to help our academic colleagues/administrators in evaluating faculty research productivity while making important decisions such as providing merit incentives, making tenure and promotion decisions, recognizing research achievements, awarding grants, and considering career advancement decisions.

The name Dp2 index was chosen to reflect the commitment and persistence of the first three authors that contributed constructively during the development of the index. This index was developed over a period of three years with numerous trials and errors and countless drafts between 2010 and 2013. The Dp2 index was originally conceptualized by the first author (Dev) for assessing faculty research productivity, thus the first letter “D,” and it was operationalized and refined by the second and third authors (Parsa and Parsa), thus “2p.” As a result, the index was left with the current name the Dp2 index.

The proposed Dp2 index takes into consideration total number of publications, total number of citations, longevity, and consistency, by calculating faculty rankings by various criteria including number of citations per publication per year over an extended period.

\section{Dp2 Index:}


An aggregate of the average of ranking for number of citations, number of publications, number of citations per publication, and number of citations per publication per year over an extended period.

where

\author{
Number of Citations $=$ Quality of research output \\ Number of Publications $=$ Quantity of research output \\ Citations per Publication $=$ Consistency of quality research output \\ Citations per Publication per Year over an extended period = Longevity of quality \\ research
}

The Dp2 index is designed to accurately reflect the productivity efforts necessary to pursue high-quality refereed research publication over a long period by a faculty member. Since high quality, high quantity, consistency, and longevity are the most important criteria for evaluating faculty research; all four factors are included in the Dp2 index.

\title{
Methodology
}

For the current study, we used Publish or Perish as a secondary data source for assessing faculty research productivity using the abovementioned criteria. Currently various other data sources are available for evaluating the research productivity of hospitality faculty members, including ORCID, SCOPUS, and Google Scholar Analytics. Some of these sources have inherent limitations including limited accessibility and lack of parsimony. In contrast, Publish or Perish is easy to use and much more accurate. Although, we have used Publish or Perish data for 
the current study, other data sources such as Google Scholar could also be used with equal efficiency and ease.

\section{Operationalizing $\mathrm{Dp} 2$ index factors}

We operationalized the four faculty productivity factors as follows:

\section{(1) Number of Quantity (Number of Publications):}

We considered all refereed academic publications in relevant fields using secondary sources. To keep the data clean and avoid unnecessary noise, we used refereed journal publications exclusively, and we did not include conference presentations, invited articles, book chapters, textbooks, working articles, proceedings, research notes, extended abstracts (usually with 2000 or fewer words), conference reports, book reviews, or consulting reports. This criterion is supported by the norm of tenure and promotion policies of institutions of higher education to rely primarily on number of refereed journal publications for all personnel decisions for promotion. While we agree that some academic institutions prefer to consider all publications including conference articles, books, book chapters, research reports, etc. while making important promotion, merit and tenure decisions, we chose to leave these out to keep the analysis simple and uncluttered. However, the proposed Dp2index is flexible enough to allow such a variation if so desired in assessing faculty productivity. Institutions that prefer to include conference articles, presentations, books, and other forms of research dissemination have the option of considering them while using this index. The proposed Dp2 index is also flexible enough to allow adaptation by academic professionals and faculty to meet their individual needs.

(2) Number of Quality (Number of Citations): 
For measuring quality of research, we included all citations for the publications chosen using the above mentioned criterion for selecting refereed publications. Thus, we did not include citations for non-refereed publications, books, conference proceedings, book chapters, and so on. Again, the proposed index allows educators to customize their own individual analyses by incorporating other citations of their choice. This flexibility is important, especially for administrators who are interested in assessing the productivity of a large group of faculty using their own institution-specific guidelines.

\section{(3) Consistency:}

Again we have used criteria often used by major hospitality-tourism programs in assessing faculty research productivity. One of the critical factors in evaluating faculty research output is consistency, making sure there are no major research publication gaps during the period under consideration. A research gap can be best described as a "dry spell” during which no refereed journal articles are published for a period of one academic year or longer. In other words, we have included only those candidates who published in refereed academic journals without any major research gaps over a period of 10 years.

\section{(4) Longevity:}

We chose a 10-year period as a reasonable choice for longevity based on promotion-andtenure guidelines from 10 major hospitality-tourism programs in the USA. Most major hospitality programs in the USA consider six years the norm for promotion from assistant to associate professor rank. For promotion from associate professor to full professor, most universities have a norm of waiting five to six years beyond the associate professorship, 
supported by high-quality research productivity with consistency and longevity. In addition, typically in promotion and tenure decisions, any major gaps in research publication streams are considered less than desirable.

As a part of this research, we observed that some universities do not have a minimum required waiting period for promotion from associate professor to full professor. For example, a major university in USA located in the central Florida area with a large hospitality program, doesn’t have a minimum waiting period for promotion from associate to full professor. That means, theoretically, at this university, one can become a full professor immediately after being promoted as an associate professor without any waiting period. Such a low regard for longevity in research productivity and scholarship is an aberration rather than a norm. Thus, consistent high-quality research for a period of 10 years was considered a good choice as it exceeds the sixyear minimum required for tenure and promotion to the associate professor level and is slightly below the often required 12-year period for the rank of full professor. Administrators who prefer to modify this period of 10 years could do so and still use the index effectively as it measures faculty productivity comparatively. For instance, academic institutions may use any period of their choice other than 10 years and the proposed Dp2 index allows such an adaptation. When the denominator is applied consistently across all tests with varying numerators, the resulting outcomes can be compared with confidence. The proposed index permits such an adjustment.

In summary, the Dp2 index is calculated by the following steps. In the first step, each researcher was ranked on four criteria; number of publications; number of citations; number of citations per publications; number citations per publication per year. Then weighted average was calculated using values for four rankings. The obtained mean of four rankings forms the Dp2 Index. 


$$
\begin{aligned}
& \text { Dp2 Index = Ranking for (Quantity + Quality + Consistency + Longevity)/4 } \\
& \text { Dp2 Index } * \text { Rankings presented in Columns }(C+E+G+I) / 4 \\
& { }^{*}=\text { weights for all variables are considered equal }
\end{aligned}
$$

Where C, E, G, and I are column labels from Table 1.

This step assumes equal weights to the four categories included in the calculating the Dp2 Index. In this article, we weighted all four included categories equally. This is not mandated; an institution or an individual can choose to weigh the included criteria unequally if their specific situation demands such a correction. If an individual or an institution prefers to place different weights, then the proposed Dp2 index allows such an adaptation. We illustrate this point with the following examples. If a faculty member was on a maternity leave, medical leave, on an administrative assignment, on sabbatical leave or other approved absence from active research, then the weights used for consistency can be adjusted to correct for the unexpected gap in research. Another example could be where a faculty member publishes high-quality research in a new or an emerging field, he/she could be given a different weight for number of citations criteria to correct for low citations often noted in emerging fields. Similarly, different weights could be considered for other criteria also. In essence, one can adapt the proposed index to meet the specific needs of an individual or an institution by considering unequal weights for each included criteria. This can be accomplished as presented in the following steps. In the next step, we present you an equation where research productivity variables have unequal weights as shown below.

$$
\text { Dp2 Index }{ }^{*}=\left(b_{1} * C+b_{2} * E+b_{3} * G+b_{4} * I\right)
$$


Where C, E, G, and I are column labels from Table 1.

Where $b_{1}+b_{2}+b_{3}+b_{4}=1$, and values for $b_{1}, b_{2}, b_{3}$, and $b_{4}$ are not necessarily equal. The values for b1; b2; b3; and b4 may vary depending on the specific needs of individual institutions.

\section{Why Publish or Perish?}

We have mentioned several potential sources of faculty productivity data other than the source we chose, Publish or Perish. Before we present the results of our study we digress briefly to explain the differences among these sources.

Google Scholar includes all academic and popular media sources thus making it cumbersome to perform analysis. Sometimes Google Scholar does not include sources of citations that might compromise the integrity of the data. Web of Science was established by Eugene Garfield in the 1960s and is one of the oldest sources for citation analysis. Although it is worldwide in its coverage, Web of Science tends to be biased towards North America. In addition, Web of Science tends to favor ISI journals.

SCOPUS was introduced by Elsevier publishers in 2004. Although it is also worldwide in its coverage it charges fees for access. It is a much better source than Web of Science for citations in the social sciences (Harzing, 2011). According to a study by Bakkalbasi, Bauer, Glover, and Wang (2006), three research analytics tools_-SCOPUS, Google, and Web of Science, resulted in three different counts for any given faculty member. All three analytical tools were in an evolving phase at the time of the study and they continue to evolve and be refined. 
For the record, SCOPUS includes more international journals than the Web of Science, and is supported by the search engine Scirus, which was developed exclusively for Elsevier. According to Bakkalbasi et al. (2006), "Web of Science does not automatically search for common word variations, while Scopus and Google Scholar do. Similar keyword searches in Scopus and Web of Science often return relatively small result sets (less than one hundred records), while the same search in Google Scholar may return hundreds of results. For example, a search for the phrase 'complementary medicine' with the word 'obesity’ returns 9 results in Scopus, 6 in Web of Science and 596 results in Google Scholar.” As stated by Meho and Yang (2007), "Results show that Scopus significantly alters the relative ranking of those faculty that appear in the middle of the rankings and that Google Scholar stands out in its coverage of conference proceedings as well as international, non-English language journals. The use of Scopus and Google Scholar, in addition to WoS, helps reveal a more accurate and comprehensive picture of the scholarly impact of authors” (p. 2105).

Another tool for analyzing faculty research productivity is Open Research Contributor IDentification (ORCID). According to Haak, Fenner, Paglione, Pentz, and Ratner (2012), ORCID is designed to avoid confusion over the similarity of names across and within disciplines. Similar names may also contribute to invalid and erroneous attribution of research. This situation could be frustrating to publishers, authors, and university administrators as they try to assess faculty research productivity. The unique identification number selected by an author remains permanently associated with that particular researcher. "For any identifier to be effective, it must be widely adopted by the research community—not only among individuals but also at the touch points where research findings are disseminated: publication submission, dataset deposition, research grant and contract applications, faculty and staff profiles, patent 
applications, etc.” (Haak et al., 2012). Although ORCID may be a novel and innovative idea, it also has some limitations. Very often faculty research is counted multiple times as researchers, media, journals, and the home institution continue to report research publication using the same unique identification number (Bilder, 2011). That means there is a clear possibility of someone’s research being counted more than once, thus affecting the accuracy of the reported results. Such duplication also places responsibility on individual researchers to carefully and periodically review all citations and remove duplications. Such a suggestion, however noble it might be in theory, is extremely difficult to implement. In addition, some researchers cannot afford to spare precious research time to undertake such tedious and unrewarding tasks.

Finally, Harzing's Publish or Perish was introduced in 2006 to overcome some of the abovementioned limitations. Publish or Perish is an open access citation analysis tool that focuses on refereed academic publications. It provides very accurate citations of refereed publications for all fields, including the total number of publications, the total number of citations, citations per year, sources of publications, and various citation metrics such as the hindex, the g-index, the hc-index, and hInorm as well as total number of years. While we have chosen Publish or Perish for publication and citation data analysis, we encourage faculty to use other data sources to test the effectiveness of the proposed Dp2 index.

\section{Data collection:}

Data for the current study were collected in November 2012 using Publish or Perish citation analysis data. The primary purpose of this article is not to evaluate or rank hospitality journals or faculty but to develop an index for measuring the research impact of hospitality faculty. First, we selected faculty members from research universities across the globe using 
Park et al. (2011), which was published in the Journal of Hospitality and Tourism Research. In the article, Park et al. listed top 50 hospitality research faculty based on their research productivity for the first decade of the twenty-first century. The practice of selecting already existing faculty rankings has precedence in Hirsch (2005). Thus, based on the faculty rankings developed by Park et al. we have included the top 50 hospitality researchers in our data set. After identifying the top 50 hospitality researchers from Park et al. (2011) study, we calculated the four elements of the Dp2 index for each faculty member using Publish or Perish data for November 2012. The collected data were imported into an Excel file and the Dp2 index was calculated for each faculty member. Based on the resulting Dp2 index, each hospitality scholar was ranked based on the quantity, quality, consistency, and longevity of his or her research output.

\section{Results and Discussion}

By presenting separate faculty listings for each of the four criteria that are used to calculate the Dp2 index first, and then listing the results of aggregating the individual scores according to the Dp2 index, we can demonstrate the changes that occur in faculty assessment depending on the criterion used. All results are presented in Excel format and the consideration period includes calendar years between 2001 and 2010.

For comparison purposes, we also ran the analysis for a 20-year from 1991 through 2010. Unfortunately, the analysis revealed that a majority of hospitality faculty from the current dataset started publishing refereed articles only after 2000. Hence, we were able to run a more meaningful test of the Dp2 index by analyzing data for the 10-year period (2001-2010). This situation could also be interpreted as reflecting the epistemologically early stages in the 
evolution of the hospitality discipline, which gained academic recognition only in the latter part of the twentieth century and became well established only in the first decade of twenty-first century.

Table 1 presents scholar rankings based, respectively, on number of publications, number of citations, number of citations per publication, number of citations per publication per year over a 10-year period, and a calculation of the Dp2 index encompassing all four criteria.

In the current study, as presented in Table 1, scholar listings differed markedly when quality (number of citations, columns B and C) and quantity (number of publications, columns D and E) were chosen as the criteria on which to base the rankings. Note that, a person who was listed first in total number of publications (quantity) was not listed first in total number of citations (quality) and vice versa. One would expect this as high number publications does not necessarily imply high number of citations as citations reflect the quality of the publication and how others perceive the article. Number of citations is a measure of the quality of research. Similar differences were found between listings based, respectively, on the quality and quantity criteria for the remaining faculty listed. Hospitality faculty and administrators must take this limitation into consideration when using these two criteria. When a faculty member or an administrator uses one of these criteria exclusively, the obtained results will be less than objective and may seriously harm the academic career of an individual, especially when used for promotion and tenure decisions (Harzing, 2011). For example, recently one of the hospitality faculty members at a major university in Central Florida, USA was denied promotion to the rank of full professor solely based on total number of citations criterion (Parsa, 2010, Personal communication with the Dean of the hospitality management program). This faculty member 
later has won the Lifetime Research Achievement Award indicating the limitation of using citations exclusively.

Consistency in quality research output was calculated by dividing the total number of citations by the total number of publications over a 10-year period. This criterion for evaluating faculty research output may be perceived as a more rigorous tool for evaluating faculty research output than either quality or quantity alone (columns F and G). The rationale for using a 10-year baseline was presented earlier in this article. This metric is designed to measure the quality of the research impact of a given faculty member over a longer period. This rigorous measure of research impact over a longer period (number of citations per publication) has resulted in very different rankings compared with the results obtained using only the quantity and quality measures. This observed discrepancy is not surprising. In fact, we expected it to be different since it measures quality impact over a longer period.

Administrators and faculty members who are interested exclusively in high-quality research impact are advised to use this consistency measure, which is more appropriate for evaluating research scholars, post-docs, research center and research institute staff, and so on, where high- quality research productivity over a long period is the primary objective. It may also help in evaluating a faculty member seeking promotion to full professor with over 10 years of research experience. Nevertheless, this ranking may not be appropriate for evaluating assistant professors or young researchers with shorter research careers and insufficient time to achieve high numbers of research citations. It is in the nature of academic publishing that there will always be a time lag between the publication of an article and its citations. The longer an article is in publication, more likely it will be cited more often, but the relationship between number of citations and number of years an article in of publication is not necessarily linear. Citation is an 
indication of quality of an article, so articles of low quality are less likely to be cited irrespective of the longevity.

The next step in fully applying the Dp2 index is calculation of consistency and longevity using number of citations per publication per year over a 10-year period (Columns $\mathrm{H}$ and I). This measure of long-term research impact also has some limitations. A typical ranking assumes that citations and publications carry equal weight. Moreover, prolific publishers of articles in refereed journals are often penalized by this criterion, as a larger denominator (number of publications) leads to a lower ratio. In addition, prolific publishers of refereed articles are penalized in yet another way since citations have a time lag between the publication date and the occurrence of citations. Moreover, faculty members who publish fewer high-quality publications at the expense of quantity are better rewarded when this criterion is used, as it will have a smaller denominator (fewer publications).

To address some of these limitations, we used the criterion of a minimum two publications per year for 10 years. In other words, any faculty member who had failed to achieve a minimum of 20 refereed publications over a 10-year period (10 years $\times 2$ articles per year) was not included in the data set. By requiring a minimum of 20 publications from 2001 through 2010, we eliminated faculty who had been publishing high-quality refereed articles in high quantity but did not meet the longevity criterion of 10 years. This condition, which was used to address the issue of consistency and longevity, is also consistent with the expected number of refereed articles published for tenure and promotion decisions at a majority of hospitality programs (two refereed articles per year is the minimum required) in the United States.

In addition, we also deleted the names of faculty members exhibiting major research gaps with no refereed publications over a one year or longer from 2001 through 2010. Again, this 
assumption is consistent with the normal standards for tenure and promotion policies of major hospitality programs in the United States. This step has resulted in the elimination of some faculty members for the next step, resulting in a total of 32 faculty members in the final analysis in Table 1 and Table 2. The results are presented in Table 2 (columns $\mathrm{J}$ and $\mathrm{K}$ ), which shows the rankings of hospitality faculty on four criteria and the Dp2 index. Listing of hospitality faculty by the Dp2 index alone is presented in the far right column.

As we present the Dp2 index, a word of caution is warranted here. In Table 1, the listings in columns $\mathrm{G}$ and I are similar. This can be explained by the fact that, in the first analysis, we chose 10 years as the specified period in developing the Dp2 index. As a result, the research productivity of each hospitality faculty member is divided by 10 , thus leading to the same ranking. In addition, we also eliminated faculty who did not have a minimum of 20 publications over a 10-year period.

The resulting Dp2 index for hospitality scholars that made the cut based on criteria specified above presented in Table 2, provides an assessment of their research productivity based on quantity, quality, consistency, and longevity of the top 32 hospitality scholars. The findings assume that all top 32 research faculty have had research careers of exactly the same length. As a result of this assumption, the rankings reported in column G and column I are identical.

The above assumption was made to simplify the calculation of the Dp2 Index initially. But in reality, all faculty do not have the same length of research careers. In other words, in one institution, different faculty members most likely to have different lengths of research careers. Thus, to reflect this realism of different lengths of research careers by the faculty of an institution, we modified the data by including a variable called number of years of publication (Column H, Table 2). This variable was added (Column H, Table 2) solely for the purpose of 
illustrating the methodology and applicability of the proposed index. As a result, the denominator was modified from a constant 10 year to a varying number of years in calculating the product in Column I (Table 2). Consequently, in Table 2, the results reported in column G and column I now are different from each other. This clearly demonstrates the effectiveness and applicability of the proposed index in assessing faculty research productivity over a long term.

The results reported in Table 2 more realistically reflect the fact that all researchers’ career lengths are not identical. As one can see, the Dp2 index performs effectively when faculty under consideration have varying research tenures (Table 2). Thus, the Dp2 index presented in the Table 2 can be adapted easily to meet the needs of any academic institution when assessing the research productivity of its faculty with varying research tenures (with at least XX years of tenure which is at the discretion of the institution), and it can also be applied effectively when evaluating faculty across disciplines.

As an example of application of Dp2 index in assessing faculty research productivity, we present Table 3. The included Table 3 clearly demonstrates how Dp2 can be applied effectively when comparing faculty research productivity across institutions and within the same discipline. In this case, the included data are truly international in scope presenting faculty in hospitality discipline across the globe. It also shows the effectiveness of Dp2 index in assessing global education for a specific discipline. Current data includes top 32 faculty members with hospitality as their primary research focus. Again, our purpose is not to rank the faculty but to show the usefulness of the proposed Dp2 index as a tool for assessing faculty research productivity with real faculty research data.

From the Table 3, it is obvious that exclusive dependence on any one research criterion such as number of publications, number of citations may not be the most prudent decision. 
Academic administrators could be making a major mistake in evaluating research productivity of faculty when they consider exclusively number of publications, number of citations etc. instead of= using the Dp2 index as explained by Parsa (2010, personal communication). Moreover, Dp2 index also provides an additional comparative assessment tool to the faculty in preparing their dossier for tenure and promotion considerations.

\section{Additional pedagogical uses of the Dp2 index}

Any index that is intended to evaluate a body of scholarly work must have meaningful applications in academic field beyond simple rankings. The proposed Dp2 index has several applications in academia. For instance, this index can be effectively applied in graduate education in tourism, travel and hospitality in several ways, and here are some examples.

One of the fundamental prerequisites for developing graduate education is faculty research productivity and quality of the research output of the institution (Poole, 2010, Personal communication with the Senior Associate Dean of Graduate College at one of the largest universities in the USA). Any proposed graduate program is expected to have academic rigor in the curriculum, demonstrate research productivity of the faculty, resource availability (physical, library and academic), meet or exceed the stringent administrative requirements that are meant to ensure continuity, growth and development of a graduate program in the long run, and demonstrate epistemological roots and existence of sufficient body of scientific knowledge through published research (Olsen, 2006, Personal communication with late Dr. Olsen regarding evolution of graduate education in hospitality and tourism; Poole, 2010, personal communication). Most academic institutions require listing of faculty research output for a recent five year period while considering any graduate program proposals. From the above discussion, 
it is clear that faculty research productivity is a primary criterion in evaluating graduate programs.

One of the effective ways to demonstrate the quantity and quality of research productivity is use an index that compares the host institution with its benchmark institutions. Such an index must be perceived as being parsimonious, effective and useful. The proposed Dp2 index effectively serves the needs of graduate programs while proposing new programs or revising existing programs. The proposed index could be very helpful in demonstrating the competitive advantage of a graduate program in faculty research compared to its benchmark institutions since it uses publicly available secondary data such as Publish or Perish, Google Scholar, etc.

This index also can also be used to promote graduate programs to prospective students as a recruitment tool, to demonstrate the quality of the faculty research compared to the competition (Severt, Tesone, Bottorff, \& Carpenter, 2009). Another use of this index is to illustrate the continuing success of the alumni as high-quality researchers in academia, industry or governmental research organizations.

An additional use of this index can be to seek funding for a graduate program or an academic institution. Most funding agencies often require proof of ranking of academic programs and faculty research productivity in quantity and quality as an evidence of demonstrated quality of the fund seeking institution. The burden of proof demonstrating quality is typically placed on the grant seeking organization. In other words, institution that is seeking external or internal competitive funding must prove that they are competitive in research productivity when compared to the peer institutions. Thus, the proposed index could be a helpful tool in demonstrating the ranking of the fund seeking institution compared to its competition in an objective manner. 
Finally, this index can also be used by individual faculty members as a part of one’s tenure and promotion dossier whenever objective rankings are either not available or useful. Whenever objective rankings are not available, faculty then can calculate the Dp2 for their specific academic unit using publicly available secondary data. Since the proposed index is based on publicly available secondary data, one can defend its usefulness and effectiveness easily and logically. Thus, the proposed index can be described as an effective tool that efficiently meets the needs of not only academic institutions but also individual faculty.

\section{Conclusion}

This article introduces a new index for measuring the research productivity of hospitality faculty. The Dp2 index is presented as a better alternative to the traditional indices of faculty research impact. The proposed Dp2 index is more comprehensive and inclusive than other indices, which have relied primarily on number of publications, number of citations, or citations per publication rather than combining such measures. The Dp2 index addresses the issue of consistency and longevity without jeopardizing highly productive faculty with high numbers of publications. It overcomes some of the limitations of the other indices and offers a more longterm view of faculty productivity. In addition, it is relatively easy to use and calculate the Dp2 index compared with the other indices, and it is comprehensive.

One of the important features of the proposed index is its flexibility and customizability, which enable academic institutions to easily adapt the index to their unique needs. For example, teaching institutions can adapt the proposed index by incorporating faculty teaching evaluations into the equation. Similarly, research-intensive institutions could customize the index by weighting individual components, and the degree of the weights can also be customized 
depending on need. Since the proposed index does not require complex algorithms or programming, it can be easily applied using Microsoft Excel. Thus the simplicity and adaptability of the proposed index are its major strengths, making it suitable for large as well as small institutions. Moreover, it can be used to compare faculty productivity across disciplines. In the current article, the authors have used 10 years in Table 1 as the basis of longevity, only for mathematical convenience and illustration. Interested institutions could customize the index to their specific needs by choosing another time base that best meets their need (see the example in Table 2).

Some administrators might be interested in including the ability to secure grants as another measure of research productivity (Chon, 2013, Personal communication with Dr. Kaye Chon, Dean, School of Hotel and Tourism Management, Hong Kong Polytechnic University, at the 18th Graduate Education and Graduate Student Research Conference in Hospitality-Tourism, Seattle, WA). The proposed Dp2 index is capable of accommodating a grants criterion also. To include research grant productivity in the calculation of the Dp2 index, one could compare an individual's grant contribution with the research grant productivity of the institution or a comparable faculty set. Thus, the current Dp2 index is flexible enough to accommodate customization to meet the specific needs of an institution, administration, discipline, or researcher. It is an effective tool for measuring research output, especially when considering promotion for a faculty member with over 10 years of research activity.

Similar to the other indices we have mentioned, the Dp2 index is also subject to limitations. In its current form, the Dp2 relies on Publish or Perish as its data source. Thus, it is highly recommended that it be further tested with other data sources such as Google Scholar and 
SCOPUS. Further testing of the Dp2 Index using data from other disciplines is highly recommended to verify its applicability across disciplines.

While developing the proposed Dp2 index, we have made a deliberate choice to use the research productivity of only hospitality faculty. This article did not divulge the names of any of the faculty included here during the review process. It was done with the approval and permission of the editor to maintain the integrity of the review process. Names of faculty included here are camouflaged as alphabets to limit the possibility to deciphering the research record of the faculty under consideration. It was done to maintain the anonymity of the faculty. Only after successful completion of the review process and paper acceptance, faculty names were included in one of the tables. Second, it is not our intention to simply rank the faculty but to demonstrate the usefulness of the proposed index. Since the focus of the current journal is teaching in tourism and travel, we deliberately chose the research records of hospitality faculty, a related field. We made this choice of using research productivity of hospitality faculty instead of tourism/travel faculty to avoid any possibility of divulging the names of the faculty considered here. Future studies could consider the research productivity of travel and tourism faculty in testing the extension or application of the proposed index.

A final word of caution is warranted here. The proposed Dp2 index is a relative score, and thus it is affected by the nature of the database used. For example, a Dp2 index calculated for one institution would be different from the Dp2 index developed from a larger database across various institutions. Similarly, the Dp2 index could vary across disciplines because what is an appropriate measure of research productivity and quality is unique for every discipline. 


\section{References}

Adkins, D., \& Budd, J. (2006). Scholarly productivity of U.S. LIS faculty. Library \& Information Science Research, 28(3), 374-389. doi:10.1016/j.lisr.2006.03.021

Amin, M., \& Mabe, M. (2000). Impact factors: Use and abuse. Perspectives in Publishing. ISI Journal Publishing Reports. London: Elsevier Publications.

Bakkalbasi, N., Bauer, K., Glover, J., \& Wang, L. (2006). Three options for citation tracking: Google Scholar, Scopus, and Web of Science. Biomedical Digital Libraries, 3(7). doi:10.1186/1742-5581-3-7. Retrieved November 16, 2013, from: http:/www.biodiglib.com/content/3/1/7

Beck, J., Kim, S. H., \& Schmidgall, R. (2011, July 27). The rating of hospitality journals for influence on salary, reappointment, promotion, and tenure decisions in international hospitality programs. Paper delivered at 2011 ICHRIE Conference, Denver, CO.

Bilder, G. (2011). Disambiguation without de-duplication: Modeling authority and trust in the ORCID system. Retrieved November 20, 2013, from: http://0labs.crossref.org.oasis.unisa.ac.za/wp-content/uploads/2013/04/disambiguationdeduplication_wp_v4.pdf

Blair, D. W., Cottle, R. L., \& Wallace, M. S. (1986). Faculty ratings of major economics departments by citations: An extension. The American Economic Review, 76(1), 264267.

Bloom, M., \& Klein,W. C. (1995). Publications and citations: A study of faculty at leading schools of social work. Journal of Social Work Education, 31(3), 377-387. 
Brown, L. D., \& Gardner, J. C. (1985). Applying citation analysis to evaluate the research contributions of accounting faculty and doctoral programs. Accounting Review, 60(2), $262-277$.

Btista, P. D., Campitelli, M. G., Konouchi, O., \& Martinex, A. S. (2006). Is it possible to compare researchers with different scietific interests? Scientometrics, 68(1), 179-189.

Chang, C. L., \& McAleer, M. (2012, January). Citations and impact of ISI tourism and hospitality journals. Tourism Management Perspectives, 1, 2-8.

Clarke, M. (2002). Some guidelines for academic quality rankings. Higher Education in Europe, 27(4), 443-459.

Davis, P., \& Papanek, G. F. (1984). Faculty ratings of major economics departments by citations. The American Economic Review, 74(1), 225-230.

Egghe, L. (2006). Theory and practice of the g-index. Scientometrics, 69(1), 131-152.

Elliott, A., Morgan, K., Fuqua, R. W., Ehrhardt, K., \& Poling, A. (2005). Self- and crosscitations in the Journal of Applied Behavior Analysis and the Journal of the Experimental Analysis of Behavior: 1993-2003. Journal of Applied Behavioral Analysis, Winter, 38(4), 559- 563.doi::10.1901/jaba.2005.133-04

Fälthammar, C. G., \& Dessler, A. J. (2013). Hannes Alfven 1908-1995. Biography posted at the School of Electrical Engineering, Alfvén Laboratory, Royal Institute of Technology (KTH), Sweden. Retrieved from: http://www.alfvenlab.kth.se/hannes.html

Ferreira, R. R., DeFranco, A. L., \& Rappole, C. L. (1994). Rating the hospitality journals. International Journal of Hospitality Management, 13(3), 209-218. doi:10.1016/02784319(94)90021-3 
Garfield, E. (1979). Is citation analysis a legitimate evaluation tool? Scientometrics, 1(4), 359375. doi:10.1007/bf02019306

Haak, L. L., Fenner, M., Paglione, L., Pentz, D., \& Ratner, H. (2012). ORCID: A system to uniquely identify researchers. Learned Publishing, 25(4), 250-264.

Hall, M. C. (2011). Publish and perish? Bibliometric analysis, journal ranking and the assessment of research quality in tourism. Tourism Management, 32(1), 16-27. doi:10.1016/j.tourman.2010.07.001

Hamermesh, D. S., Johnson, G. E., \& Weisbrod, B. A. (1982). Scholarship, citations, and salaries: Economic rewards in economics. Southern Economic Journal, 49 (2), 472-481.

Harzing, A.-W. K. (2011). The publish or perish book: Your guide to effective and responsible analysis. Melbourne: Tarma Software Research Pty.

Harzing, A.-W. K., \& van der Wal, R. (2008). Google Scholar as a new source of citation analysis? Ethics in Science and Environmental Politics, 8(1), 62-71.

Hayes, R. M. (1983). Citation statistics as a measure of faculty research productivity. Journal of Education for Librarianship, 23(3), 151-172.

Hirsch, J. E. (2005). An index to quantify an individual research output. Proceedings of National Academy of Sciences, 102(46), 16569-16572.

Hubbard, R., Norman, A., \& Parsa, R. A. (2010). Marketing’s ‘Oscars’: A citation analysis of award- winning articles. Marketing Intelligence and Planning, 28(5), 669-684.

Iyengar, S. (2010). The art of choosing. New York, NY: Twelve Hatchette Group. Jamal, T., Smith, B., \& Watson, E. (2008). Ranking, rating and scoring of tourism journals: Interdisciplinary challenges and innovations. Tourism Management, 29(1), 66-78. doi:10.1016/j.tourman.2007.04.001 
Jogaratnam, G., McCleary, K. W., Mena, M. M., \& Yoo, J. J. E. (2005). An analysis of hospitality and tourism research: Institutional contributions. Journal of Hospitality \& Tourism Research, 29(3), 356-371.

Kostoff, R. (1998). The use and misuse of citation analysis in research evaluation. Scientometrics, 43(1), 27-43. doi:10.1007/bf02458392

Law, R., \& Chon, K. (2007). Evaluating research performance in tourism and hospitality: The perspective of university program heads. Tourism Management, 28(5), 1203-1211. doi:10.1016/j.tourman.2006.09.022

Law, R., Leung, R., \& Buhalis, D. (2010). An analysis of academic leadership in hospitality and tourism journals. Journal of Hospitality \& Tourism Research, 34(4), 455-477. doi:10.1177/1096348010370866

Law, R., \& van der Veen, R. (2008). The popularity of prestigious hospitality journals: A Google Scholar approach. International Journal of Contemporary Hospitality Management, 20(2), 113-125.

Losekoot, E., Verginis, C. S., \& Wood, R. C. (2001). Out for the count: Some methodological questions in 'publications counting' literature. International Journal of Hospitality Management, 20(3), 233-244.

McKercher, B. (2005). A case for ranking tourism journals. Tourism Management, 26(5), 649651. doi:10.1016/j.tourman.2004.04.003

McKercher, B. (2012). Influence ratio: An alternate means to assess the relative influence of hospitality and tourism journals on research. International Journal of Hospitality Management, 31(3), 962-971. doi:10.1016/j.ijhm.2011.11.004 
McKercher, B., Law, R., \& Lam. T. (2006). Rating tourism and hospitality journals. Tourism Management, 27(6), 1235-1252. doi:10.1016/j.tourman.2005.06.008

Meho, L. I., \& Sonnenwald, D. H. (2000). Citation ranking versus peer evaluation of senior faculty research performance: A case study of Kurdish scholarship. Journal of the American Society for Information Science, 51(2), 123-138.

Meho, L. I., \& Yang, K. (2007). Impact of data sources on citation counts and rankings of LIS faculty: Webof Science versus SCOPUS and Google scholar. Journal of the American Society for Information Science and Technology, 58(13), 2105-2125.

Murthy, G.S. (2010). Personal communication with a student of Prof. Alfen.

Park, K., Phillips, W. J., Canter, D. D., \& Abbott, J. (2011). Hospitality and tourism research rankings by author, university, and country using six major journals. Journal of Hospitality \& Tourism Research, 35(3), 381-416. doi:10.1177/1096348011400743

Parsa, H.G. (2010). Personal communication with the Dean of a major hospitality program in Florida.

Pechlaner, H., Zehrer, A., Matzler, K., \& Abfalter, D. (2004). A ranking of international tourism and hospitality journals. Journal of Travel Research, 42(4), 328-332. doi:10.1177/0047287504263026

Reed, K. L. (1995). Citation analysis of faculty publication: Beyond Science Citation Index and Social Science Citation Index. Bulletin of the Medical Library Association, 83(4), 503508.

Roche, T., \& Smith, D. L. (1978). Frequency of citations as criterion for the ranking of departments, journals, and individuals. Sociological Inquiry, 48(1), 49-57. 
Rutherford, D. G., \& Samenfink, W. (1992). Most frequent contributors to the hospitality literature. Journal of Hospitality \& Tourism Research, 16(1), 23-39. doi:10.1177/109634809201600103

Ryan, C. (2005). The ranking and rating of academics and journals in tourism research. Tourism Management, 26(5), 657-662. doi:10.1016/j.tourman.2004.05.001

Schmidgall, R. S., \& Woods, R. H. (1993). Rating of publishing channels by hospitality faculty. Journal of Hospitality \& Tourism Research, 16(3), 89-103. doi:10.1177/109634809301600308

Severt, D. E., Tesone, D. V., Bottorff, T. J., \& Carpenter, M. L. (2009). A world ranking of the top 100 hospitality and tourism programs. Journal of Hospitality \& Tourism Research, 33(4), 451-470. doi:10.1177/1096348009344210

Sheldon, P. J. (1990). Journals in tourism and hospitality: The perceptions of publishing faculty. The Journal of Tourism Studies, 1(1), 42-48.

Stremersch, S., Verniers, I., \& Verhoef, P. C. (2007). The quest for citations: Drivers of article impact. Journal of Marketing, 71(3), 171-193.

Thompson, D. F., Callen, E. C., \& Nahata, M. C. (2009). New indices in scholarship assessment. American Journal of Pharmacological Education, 73(6), 111-112.

Way, K. A., Harrington, R. J., \& Ottenbacher, M. C. (2012). Hospitality author and university productivity in the 21st century. Journal of Culinary Science \& Technology, 10(3), 239258. 
Table 1. Top 32 Hospitality Faculty Members by Research Impact Using Four Criteria: Quantity, Quality, Consistency, and Longevity

\begin{tabular}{|c|c|c|c|c|c|c|c|c|c|c|}
\hline \multirow{2}{*}{\multicolumn{11}{|c|}{$\begin{array}{l}\text { Hospitality Top } 32 \text { Authors } \\
\text { Number of Publications \& Citations between } 2000 \text { and } 2010\end{array}$}} \\
\hline & & & & & & & & & & \\
\hline A & B & $\mathrm{C}$ & $\mathrm{D}$ & $E$ & $\mathrm{~F}$ & $\mathrm{G}$ & $\mathrm{H}$ & I & $\mathrm{J}$ & $\mathrm{K}$ \\
\hline Name & $\begin{array}{r}\text { Total \# Citations } \\
\text { 2000-2010 }\end{array}$ & Rank & $\begin{array}{c}\text { Total \# Publications - } \\
\text { 2000-2010 }\end{array}$ & Rank & $\begin{array}{r}\text { Citations per } \\
\text { Pub }\end{array}$ & Rank & $\begin{array}{r}\text { Citations per Pub } \\
\text { per Year }\end{array}$ & Rank & Dp2 Index & FINAL Ranking \\
\hline AAA & 3884 & 1 & 101 & 3 & 38.5 & 4 & 3.8 & 4 & 3 & 1 \\
\hline BBB & 1357 & 6 & 33 & 12 & 41.1 & 2 & 4.1 & 2 & 5.5 & 2 \\
\hline CCC & 1490 & 4 & 46 & 6 & 32.4 & 7 & 3.2 & 7 & 6 & 3 \\
\hline DDD & 1366 & 5 & 43 & 8 & 31.8 & 8 & 3.2 & 8 & 7.3 & 4 \\
\hline EEE & 1290 & 8 & 36 & 10 & 35.8 & 6 & 3.6 & 6 & 7.5 & 5 \\
\hline FFF & 1333 & 7 & 47 & 5 & 28.4 & 9 & 2.8 & 9 & 7.5 & 6 \\
\hline GGG & 1244 & 9 & 25 & 27 & 49.8 & 1 & 5 & 1 & 9.5 & 7 \\
\hline $\mathrm{HHH}$ & 1228 & 10 & 33 & 12 & 37.2 & 5 & 3.7 & 5 & 8 & 8 \\
\hline III & 3407 & 2 & 147 & 1 & 23.2 & 13 & 2.3 & 13 & 7.3 & 9 \\
\hline JJJ & 2122 & 3 & 102 & 2 & 20.8 & 14 & 2.1 & 14 & 8.3 & 10 \\
\hline KKK & 777 & 12 & 20 & 32 & 38.9 & 3 & 3.9 & 3 & 12.5 & 11 \\
\hline NNN & 725 & 13 & 28 & 18 & 25.9 & 10 & 2.6 & 10 & 12.8 & 12 \\
\hline $\mathrm{OOO}$ & 991 & 11 & 48 & 4 & 20.6 & 15 & 2.1 & 15 & 11.3 & 13 \\
\hline PPP & 716 & 15 & 28 & 18 & 25.6 & 11 & 2.6 & 11 & 13.8 & 14 \\
\hline QQQ & 720 & 14 & 31 & 15 & 23.2 & 12 & 2.3 & 12 & 13.3 & 15 \\
\hline VVV & 546 & 16 & 27 & 23 & 20.2 & 16 & 2 & 16 & 17.8 & 16 \\
\hline WWW & 500 & 17 & 29 & 17 & 17.2 & 17 & 1.7 & 17 & 17 & 17 \\
\hline$\overline{Z Z Z}$ & 397 & 18 & 36 & 10 & 11 & 25 & 1.1 & 25 & 19.5 & 18 \\
\hline AAAB & 396 & 19 & 31 & 15 & 12.8 & 24 & 1.3 & 24 & 20.5 & 19 \\
\hline BBBC & 363 & 22 & 22 & 30 & 16.5 & 18 & 1.7 & 18 & 22 & 20 \\
\hline EEEF & 369 & 21 & 26 & 25 & 14.2 & 21 & 1.4 & 21 & 22 & 21 \\
\hline FFFG & 379 & 20 & 46 & 6 & 8.2 & 29 & 0.8 & 29 & 21 & 22 \\
\hline GGGH & 361 & 23 & 24 & 28 & 15 & 20 & 1.5 & 20 & 22.8 & 23 \\
\hline HHHI & 353 & 24 & 22 & 30 & 16 & 19 & 1.6 & 19 & 23 & 24 \\
\hline KKKL & 345 & 25 & 27 & 23 & 12.8 & 23 & 1.3 & 23 & 23.5 & 25 \\
\hline LLLM & 316 & 26 & 23 & 29 & 13.7 & 22 & 1.4 & 22 & 24.8 & 26 \\
\hline
\end{tabular}




\begin{tabular}{|l|l|l|l|l|l|l|l|l|l|l|l|}
\hline MMMN & 266 & 27 & 28 & 18 & 9.5 & 26 & 1 & 26 & 26 & 24.3 & 27 \\
\hline OOOP & 255 & 28 & 28 & 18 & 9.1 & 28 & 0.9 & 28 & 28.5 & 28 \\
\hline PPPQ & 224 & 31 & 38 & 9 & 5.9 & 31 & 0.6 & 30 & 31 & 25.5 & 29 \\
\hline RRRS & 242 & 30 & 32 & 14 & 7.6 & 30 & 0.8 & 27 & 30 & 26 \\
\hline SSSU & 245 & 29 & 26 & 25 & 9.4 & 27 & 0.9 & 32 & 27 & 27 \\
\hline WWWX & 52 & 32 & 28 & 18 & 1.9 & 32 & 0.2 & & 32 & 28.5 \\
\end{tabular}


Table 2. Top 32 Hospitality Faculty by Research Impact Using Four Criteria: Quantity, Quality, Consistency, and Longevity, Adjusted for Length of Research Careers in Years.

\begin{tabular}{|c|c|c|c|c|c|c|c|c|c|c|}
\hline \multicolumn{11}{|c|}{ Hospitality Top 32 Authors } \\
\hline \multicolumn{11}{|c|}{ Number of Publications \& Citations between 2000 and 2010} \\
\hline A & $\mathrm{B}$ & $\mathrm{C}$ & $\mathrm{D}$ & $\mathrm{E}$ & $\mathrm{F}$ & G & $\mathrm{H}$ & $\mathrm{I}$ & $\mathrm{J}$ & $\mathrm{K}$ \\
\hline Name & \begin{tabular}{|r|} 
Total \# Citations \\
$2000-2010$ \\
\end{tabular} & Ran & $\begin{array}{c}\text { Total \# Publications - } \\
2000-2010\end{array}$ & Rank & $\begin{array}{r}\text { Citations per } \\
\text { Pub }\end{array}$ & Rank & $\begin{array}{r}\text { Citations per Pub } \\
\text { per Year }\end{array}$ & Rank & Dp2 Index & FINAL Ranking \\
\hline AAA & 3884 & 1 & 101 & 3 & 38.5 & 4 & 4.3 & 2 & 2.5 & 1 \\
\hline BBB & 1357 & 6 & 33 & 12 & 41.1 & 2 & 3.4 & 5 & 6.3 & 2 \\
\hline CCC & 1490 & 4 & 46 & 6 & 32.4 & 7 & 2.5 & 11 & 7 & 3 \\
\hline DDD & 1366 & 5 & 43 & 8 & 31.8 & 8 & 2.9 & 7 & 7 & 4 \\
\hline EEE & 1290 & 8 & 36 & 10 & 35.8 & 6 & 3.3 & 6 & 7.5 & 5 \\
\hline FFF & 1333 & 7 & 47 & 5 & 28.4 & 9 & 2.4 & 12 & 8.3 & 6 \\
\hline GGG & 1244 & 9 & 25 & 27 & 49.8 & 1 & 4.1 & 3 & 10 & 7 \\
\hline $\mathrm{HHH}$ & 1228 & 10 & 33 & 12 & 37.2 & 5 & 4.1 & 4 & 7.8 & 8 \\
\hline III & 3407 & 2 & 147 & 1 & 23.2 & 13 & 2.6 & 10 & 6.5 & 9 \\
\hline JJJ & 2122 & 3 & 102 & 2 & 20.8 & 14 & 1.6 & 16 & 8.8 & 10 \\
\hline KKK & 777 & 12 & 20 & 32 & 38.9 & 3 & 4.9 & 1 & 12 & 11 \\
\hline NNN & 725 & 13 & 28 & 18 & 25.9 & 10 & 2.9 & 8 & 12.3 & 12 \\
\hline $\mathrm{OOO}$ & 991 & 11 & 48 & 4 & 20.6 & 15 & 1.9 & 13 & 10.8 & 13 \\
\hline PPP & 716 & 15 & 28 & 18 & 25.6 & 11 & 1.8 & 15 & 14.8 & 14 \\
\hline QQQ & 720 & 14 & 31 & 15 & 23.2 & 12 & 2.6 & 9 & 12.5 & 15 \\
\hline VVV & 546 & 16 & 27 & 23 & 20.2 & 16 & 1.8 & 14 & 17.3 & 16 \\
\hline WWW & 500 & 17 & 29 & 17 & 17.2 & 17 & 1.3 & 20 & 17.8 & 17 \\
\hline ZZZ & 397 & 18 & 36 & 10 & 11 & 25 & 0.9 & 27 & 20 & 18 \\
\hline AAAB & 396 & 19 & 31 & 15 & 12.8 & 24 & 1.3 & 22 & 20 & 19 \\
\hline BBBC & 363 & 22 & 22 & 30 & 16.5 & 18 & 1.1 & 24 & 23.5 & 20 \\
\hline EEEF & 369 & 21 & 26 & 25 & 14.2 & 21 & 1.4 & 19 & 21.5 & 21 \\
\hline FFFG & 379 & 20 & 46 & 6 & 8.2 & 29 & 0.9 & 28 & 20.8 & 22 \\
\hline GGGH & 361 & 23 & 24 & 28 & 15 & 20 & 1.5 & 17 & 22 & 23 \\
\hline HHHI & 353 & 24 & 22 & 30 & 16 & 19 & 1.5 & 18 & 22.8 & 24 \\
\hline KKKL & 345 & 25 & 27 & 23 & 12.8 & 23 & 1.3 & 21 & 23 & 25 \\
\hline LLLM & 316 & 26 & 23 & 29 & 13.7 & 22 & 1.1 & 23 & 25 & 26 \\
\hline
\end{tabular}




\begin{tabular}{|l|l|l|l|l|l|l|l|l|l|l|l|}
\hline MMMN & 266 & 27 & 28 & 18 & 9.5 & 26 & 1 & 24 & 25 & 24 & 27 \\
\hline OOOP & 255 & 28 & 28 & 18 & 9.1 & 28 & 0.8 & 29 & 25.8 & 28 \\
\hline PPPQ & 224 & 31 & 38 & 9 & 5.9 & 31 & 0.7 & 29 & 30 & 25.3 & 29 \\
\hline RRRS & 242 & 30 & 32 & 14 & 7.6 & 30 & 0.6 & 27 & 31 & 26.3 & 30 \\
\hline SSSU & 245 & 29 & 26 & 25 & 9.4 & 27 & 0.9 & 26 & 26.8 & 31 \\
\hline WWW & 52 & 32 & 28 & 18 & 1.9 & 32 & 0.2 & & 32 & 28.5 \\
\hline
\end{tabular}


Table 3. An Example of Application of Dp2 Index to the Hospitality Field

\begin{tabular}{|c|c|c|c|c|c|c|c|c|c|c|c|}
\hline \multicolumn{12}{|c|}{ Top 32 Hospitality Authors } \\
\hline & A & $\mathrm{B}$ & $\mathrm{C}$ & $\mathrm{D}$ & $\mathrm{E}$ & $\mathrm{F}$ & G & $\mathrm{H}$ & I & $\mathrm{J}$ & $\mathrm{K}$ \\
\hline No. & Name & $\begin{array}{l}\text { Total } \\
\text { No. of } \\
\text { Citations } \\
2000- \\
2010 \\
\end{array}$ & $\begin{array}{l}\text { Rank } \\
\text { Based on } \\
\text { Total No. } \\
\text { of } \\
\text { Citations }\end{array}$ & $\begin{array}{l}\text { Total No. } \\
\text { of } \\
\text { Publication } \\
\text { s - 2000- } \\
2010 \\
\end{array}$ & $\begin{array}{l}\text { Rank } \\
\text { Based on } \\
\text { Total No. } \\
\text { of Pubs. }\end{array}$ & $\begin{array}{l}\text { No. of } \\
\text { Citations } \\
\text { per } \\
\text { Publication } \\
\end{array}$ & $\begin{array}{l}\text { Rank } \\
\text { Based on } \\
\text { No. of } \\
\text { Citations } \\
\text { per } \\
\text { Publication } \\
\end{array}$ & $\begin{array}{l}\text { No. of } \\
\text { Citations } \\
\text { per } \\
\text { Publication } \\
\text { per Year }\end{array}$ & $\begin{array}{l}\text { Rank based } \\
\text { on No. of } \\
\text { Citations } \\
\text { per } \\
\text { Publication } \\
\text { per Year }\end{array}$ & Dp2 Index & $\begin{array}{l}\text { Final } \\
\text { Ranking }\end{array}$ \\
\hline 1 & Anna S. Mattila & 3884 & 1 & 101 & 3 & 38.5 & 4 & 3.85 & 4 & 3 & 1 \\
\hline 2 & Chekitan S. Dev & 1357 & 6 & 33 & 12 & 41.1 & 2 & 4.11 & 2 & 5.5 & 2 \\
\hline 3 & Woo Gon Kim & 1490 & 4 & 46 & 6 & 32.4 & 7 & 3.24 & 7 & 6 & 3 \\
\hline 4 & Rob Law & 3407 & 2 & 147 & 1 & 23.2 & 13 & 2.32 & 13 & 7.3 & 4 \\
\hline 5 & Cathy A. Enz & 1366 & 5 & 43 & 8 & 31.8 & 8 & 3.18 & 8 & 7.3 & 4 \\
\hline 6 & Osman M. Karatepe & 1333 & 7 & 47 & 5 & 28.4 & 9 & 2.84 & 9 & 7.5 & 6 \\
\hline 7 & Sheryl E. Kimes & 1290 & 8 & 36 & 10 & 35.8 & 6 & 3.58 & 6 & 7.5 & 6 \\
\hline 8 & Terry Lam & 1228 & 10 & 33 & 12 & 37.2 & 5 & 3.72 & 5 & 8 & 8 \\
\hline 9 & $\begin{array}{l}\text { SooCheong } \\
\text { (Shawn)Jang }\end{array}$ & 2122 & 3 & 102 & 2 & 20.8 & 14 & 2.08 & 14 & 8.3 & 9 \\
\hline 10 & Haemoon Oh & 1244 & 9 & 25 & 27 & 49.8 & 1 & 4.98 & 1 & 9.5 & 10 \\
\hline 11 & Michael C. Sturman & 991 & 11 & 48 & 4 & 20.6 & 15 & 2.06 & 15 & 11.3 & 11 \\
\hline 12 & J. Bruce Tracey & 777 & 12 & 20 & 32 & 38.9 & 3 & 3.89 & 3 & 12.5 & 12 \\
\hline 13 & Michael Lynn & 725 & 13 & 28 & 18 & 25.9 & 10 & 2.59 & 10 & 12.8 & 13 \\
\hline 14 & Ki-Joon Back & 720 & 14 & 31 & 15 & 23.2 & 12 & 2.32 & 12 & 13.3 & 14 \\
\hline 15 & Peter O'Connor & 716 & 15 & 28 & 18 & 25.6 & 11 & 2.56 & 11 & 13.8 & 15 \\
\hline 16 & Karin Weber & 500 & 17 & 29 & 17 & 17.2 & 17 & 1.72 & 17 & 17 & 16 \\
\hline 17 & Karthik Namasivayam & 546 & 16 & 27 & 23 & 20.2 & 16 & 2.02 & 16 & 17.8 & 17 \\
\hline 18 & H. G. Parsa & 397 & 18 & 36 & 10 & 11 & 25 & 1.1 & 25 & 19.5 & 18 \\
\hline 19 & Clark Hu & 396 & 19 & 31 & 15 & 12.8 & 24 & 1.28 & 24 & 20.5 & 19 \\
\hline 20 & Gary M. Thompson & 379 & 20 & 46 & 6 & 8.2 & 29 & 0.82 & 29 & 21 & 20 \\
\hline 21 & John W. O'Neill & 369 & 21 & 26 & 25 & 14.2 & 21 & 1.42 & 21 & 22 & 21 \\
\hline 22 & Michael D. Olsen & 363 & 22 & 22 & 30 & 16.5 & 18 & 1.65 & 18 & 22 & 21 \\
\hline 23 & Vincent P. Magnini & 361 & 23 & 24 & 28 & 15 & 20 & 1.5 & 20 & 22.8 & 23 \\
\hline
\end{tabular}




\begin{tabular}{|c|c|c|c|c|c|c|c|c|c|c|c|}
\hline 24 & Andrew H. Feinstein & 353 & 24 & 22 & 30 & 16 & 19 & 1.6 & 19 & 23 & 24 \\
\hline 25 & Zheng Gu & 345 & 25 & 27 & 23 & 12.8 & 23 & 1.28 & 23 & 23.5 & 25 \\
\hline 26 & Seoki Lee & 266 & 27 & 28 & 18 & 9.5 & 26 & 0.95 & 26 & 24.3 & 26 \\
\hline 27 & Linda Canina & 316 & 26 & 23 & 29 & 13.7 & 22 & 1.37 & 22 & 24.8 & 27 \\
\hline 28 & Arun Upneja & 224 & 31 & 38 & 9 & 5.9 & 31 & 0.59 & 31 & 25.5 & 28 \\
\hline 29 & Zvi Schwartz & 255 & 28 & 28 & 18 & 9.1 & 28 & 0.91 & 28 & 25.5 & 28 \\
\hline 30 & Robert J. Harrington & 242 & 30 & 32 & 14 & 7.6 & 30 & 0.76 & 30 & 26 & 30 \\
\hline 31 & Wilco W. Chan & 245 & 29 & 26 & 25 & 9.4 & 27 & 0.94 & 27 & 27 & 31 \\
\hline 32 & David S. Sherwyn & 52 & 32 & 28 & 18 & 1.9 & 32 & 0.19 & 32 & 28.5 & 32 \\
\hline
\end{tabular}

Note. Data are not adjusted for the length of faculty research careers in number of years. 